\title{
Abstracts from the literature
}

\section{Calcium entry blockers and intracranial pres-} sure

In order to examine the effects of verapamil on intracranial pressure (ICP) in patients with comprised intracranial compliance, five hypertensive patients with supratentorial tumours were given verapamil, $5 \mathrm{mg}$ intravenously, at the time of anaesthesia induction. Within four minutes, ICP increased 67 per cent from $18 \pm 4 \mathrm{mmHg}$ (S.E.) to $27 \pm 5 \mathrm{mmHg}(\mathrm{p}<0.05)$, whereas mean arterial pressure decreased 20 per cent from $111 \pm 7 \mathrm{mmHg}$ to $89 \pm 4 \mathrm{mmHg}(\mathrm{p}<0.05)$, and cerebral perfusion pressuse (CPP) decreased 33 per cent from $93 \pm$ $11 \mathrm{mmHg}$ to $62 \pm 6 \mathrm{mmHg}$ ( $\mathrm{p}<0.05$ ). The increases in ICP responded promptly to hyperventilation and intravenous lidocaine $\left(1.5 \mathrm{mg} \cdot \mathrm{kg}^{-\mathbf{l}}\right)$. A control group of five hypertensive patients with supratentorial tumours received the same anaesthetic agents without verapamil. In this group, ICP and CPP were unchanged. The authors conclude that calcium entry-blockers, such as verapamil, should be avoided in patients with compromised intracranial compliance unless ICP is being monitored and proper therapy for intracranial hypertension can be rapidly instituted. (Bedford RF, Dacey, $R$, Winn HR, Lynch C III. Adverse impact of a calcium entry-blocker verapamil on intracranial pressure in patients with brain tumors. $J$ Neurosurg 1983; $59: 800-2$ )

Ventilatory response to morphine in young and old subjects

The effects of intravenous morphine $(10 \mathrm{mg} / 70 \mathrm{~kg}$ body weight) on ventilation in two groups of subjects, young (age 28-37 years) and old (age 65-82 years) were studied prior to elective surgery. There was no significant difference between the two groups in minute ventilation, ventilatory frequency and end-tidal carbon dioxide before morphine administration. In both groups there was a significant depression of ventilation and elevation of end-tidal carbon dioxide tension 20 minutes after intravenous morphine. There was no significant difference between the two groups in the response of thesc variables to morphine. Howcver, in the older group seven out of thirteen subjects showed frequent periods of apnoea or periodic breathing whereas three of the young subjects had these phenomena at much less frequent intervals. Respiratory depression after morphine is similar in old and young patients but old patients have more change in ventilatory control. (Arunasalam $K$, Davenport $H T$, Painter $S$, Jones $J G$. Ventilatory response to morphine in young and old subjects. Anaesthesia 1983; 38: 529-33)

\section{Anticholinergics and gastric emptying}

A double-blind study of the effects of glycopynolate or atropine IV on gastric emptying was undertaken in 30 non-pregnant women. Gastric emptying, which was assessed by the uptake of orally administered paracetamol, was decreased in the patients in the first trimester of pregnancy when compared with the non-pregnant patients. Following the administration of glycopyrrolate, gastric emptying was decreased in the nort-pregnant patients and decreased further in the pregnant patients. (Clark JM, Seager SJ. Gastric emptying following premedication with glycopyrrolate cr atropine. $\mathrm{Br}$ J Anaesth 1983; 55: 1195-9)

\section{Postoperative pain therapy}

A randomized double blind trial was carried out over the first two days after thoracotomy to compare the analgesic effects of rectal indomethacin $100 \mathrm{mg}$ administered eight hourly, cryoanalgesia, and a combination of both of these with the effects of conventional intramuscular opiate analgesia. Pain scores were significantly reduced with both rectal indomethacin alone and cryoanalgesia alone; these treatments had an additive effect when used in combination. Pain on movement was significantly increased, and indomethacin was more effective in reducing this than cryoanalgesia. Groups receiving either indomethacin alone or the combination treatment required significantly less opiate on the first 
day and exhibited improved peak flow values over the first two days.

It is concluded that rectal indomethacin, in this dosage, can provide good, safe analgesia after thoracotomy with minimum administrative difficulty. When used as an adjunct to cryoanalgesia it has an additive effect. There are many potential uses for this drug in other branches of surgery. (Keenan DJM. Cave K, Langdon L, Lea RE. Comparative trial of rectal indomethacin and cryoanalgesia for control of early posthoracotomy pain. BrMed J 1983; 287: 1335-7)

\section{Management of flail chest}

This paper compares the management of two groups of patients with flail chest. The 25 patients in group 1 had a flail chest without other significant injuries or shock, whereas the 57 in group 2 had a flail chest with multiple injurics, shock or both. Patients in group 1 were treated with repeated multiple intercostal nerve blocks or high segmental epidural analgesia, oxygen, intensive chest physiotherapy, fluid restriction, furosemide diuretics, methylprednisolone sodium succinate and colloid infusion in an intensive care unit. In addition to these measures, patients in group 2 underwent endotracheal intubation and assisted mechanical ventilation with a volume respirator that provided continuous positive airway pressure and positive end-expiratory pressure. Of the 57 group 2 patients 36 required prolonged ventilation, eventually through a tracheostomy, because of severe head injury, pneumonia, severe facial injury, quadriplegia, preexisting lung disease or severe sepsis. However, tracheostomy was avoided in the other 21 patients in group 2. There were no deaths in group 1, but eight (14 per cent) of the patients in group 2 died. These results show that avoidance of tracheostomy and ventilation in selected patients with flail chest is consistent with a low morbidity and mortality. (Miller HAB, Taylor GA, Harrison AW, Maggisano $R$, Hanna S, DeLacy JL, Shuman H. Management of fail chest. Can Med Assoc J 1983; 129: 1104-7)

\section{Pulmonary oxygen toxicity}

To study the early changes in the lower respiratory tract in persons exposed to periods of hyperoxia usually considered safe, the authors evaluated 14 normal subjects by bronchoalveolar lavage before and immediately after $16.7 \pm 1.1$ hours of breathing more than 95 per cent oxygen. Hyperoxia caused a significant alveolar-capillary "leak" as detected by the presence of increased plasma albumin and transferrin in lavage fluid. These changes were reversible as shown at repeat lavage in four subjects two weeks after oxygen administration.

Hyperoxia for an average of $\mathbf{1 7}$ hours did not change the total number or type of lung inflammatory and immune effector cells recovered by lavage ( $p>0.05$, all comparisons). Howcver, alveolar macrophages from subjects exposed to oxygen released increased amounts of fibronectin (p $<0.05)$ and alveolar-macrophage-derived growth factor for fibroblasts $(p<0.01)$ - mediators thought to modulate fibroblast recruitment and proliferation in the alveolar wall.

Thus, although some of the effects of exposure to 17 hours of more than 95 per cent oxygen are reversible, hyperoxia for even this short period lowers the structural or functional barriers that normally prevent alveolar-capillary "leak" and induces processes that can culminate in fibrosis of the alvenlar wall. (Davis WB, Rennard SI, Bitterman PB, Crystal RG. Pulmonary oxygen toxicity. Early reversible changes in human alveolar structures induced by hyperoxia. N Engl J Med 1983; $309: 878-831$ 